\title{
Erratum to: The subdiaphragmatic cistern: historic and radioanatomic findings
}

\author{
Antonio Di Ieva • Manfred Tschabitscher • \\ Christian Matula $\cdot$ Fuminari Komatsu . \\ Mika Komatsu • Giovanni Colombo • Camillo Sherif • \\ Renato J. Galzio
}

Published online: 13 December 2011

(C) Springer-Verlag 2011

\section{Erratum to: Acta Neurochir}

DOI 10.1007/s00701-011-1220-1

There are some errors in the legend of Fig. 4e and Fig. 2b:

Figure 4e: "around the ostium sphenoidalis" should have read "around the ostium of the diaphragm", and "OS, ostium sphenoidalis" should be "OD, ostium of the diaphragm".

Moreover, the legend of the Figure $2 b$ should have read "Schematic representation of the coronal section of the sellar region".

The online version of the original article can be found at http://dx.doi. org/10.1007/s00701-011-1220-1.

\footnotetext{
A. Di Ieva $(\varangle) \cdot$ M. Tschabitscher

Center for Anatomy and Cell Biology, Department of Systematic

Anatomy, Medical University of Vienna,

Waehringerstrasse 13,

1090 Vienna, Austria

e-mail: diieva@hotmail.com

A. Di Ieva $\cdot$ C. Matula

Department of Neurosurgery, Medical University of Vienna,

Vienna, Austria

F. Komatsu $\cdot$ M. Komatsu

Department of Neurosurgery, Faculty of Medicine,

Fukuoka University,

Fukuoka, Japan
}

\section{G. Colombo}

Department of Otorhinolaryngology,

IRCCS Istituto Clinico Humanitas,

Milan, Italy

C. Sherif

Department of Neurosurgery, Krankenanstalt Rudolfstiftung, Vienna, Austria

\section{R. J. Galzio}

Department of Neurosurgery,

Medical School of the University of L'Aquila,

L'Aquila, Italy 